\title{
Gastronomia: cerveja dos sabores amazônicos como elemento atrativo para o turismo em Belém (PA)
}

\section{Gastronomy: beer amazonian flavors as attractive element for tourism in Belém (PA, Brazil)}

\author{
Alessandra Almeida Pereira, Brenda Cristina Lima, Diogo Domingos Santos
}

\section{RESUMO}

O presente trabalho intitulado "Gastronomia: Cerveja dos sabores amazônicos como elemento atrativo para o turismo em Belém-Pa" faz reflexões quanto a problemática do entendimento e valorização da gastronomia paraense a partir da apreciação e produção de cervejas artesanais que utilizam insumos regionais, visando destacar a cultura cervejeira e os sabores amazônicos no contexto do turismo. O objetivo é analisar a potencialidade destas bebidas como um produto indutor para 0 turismo em Belém. Para o alcance dos objetivos, a pesquisa deu-se metodologicamente pelo levantamento bibliográfico documental e pesquisa de campo. A partir da aplicação de questionários tanto para o visitante da cidade de Belém, quanto para população local, à pesquisa de campo também aferiu os empreendimentos de alimentos e bebidas da cidade. Com base nestes procedimentos, contextualiza-se conceitualmente sobre cultura, turismo, gastronomia e cerveja no âmbito mundial, nacional, regional, os quais foram fundamentais para uma reflexão mais abrangente da problemática da pesquisa. Os resultados obtidos apontam que as cervejas artesanais dos sabores amazônicos têm um alto potencial atrativo, no entanto, ainda não há planejamento turístico especifico para valorização do produto. Desse modo contribuiu-se com os estudos acerca dessa relação que há entre o turismo e gastronomia na cidade de Belém. Ao final desse trabalho foi sugerida a ampliação da divulgação deste produto para população local, a criação de um roteiro cervejeiro. De modo, a colocar a cidade de Belém na rota mundial das cervejas artesanais.

PALAVRAS-CHAVE: Turismo; Gastronomia; Belém; Cerveja e Sabores Amazônicos. 


\section{ABSTRACT}

This work entitled "Gastronomy: Beer Amazonian flavors as attractive element for tourism in Belém-Pa" shows how problematic the understanding and valorization of Pará cuisine from the appreciation and production of craft beers using regional raw materials, aiming to highlight the beer culture and the Amazonian flavors. So that aims to analyze the potential of these drinks as an inductor product for tourism in Belém. This work was methodological basis, bibliographic and documentary surveys and field research. From the questionnaires both for the visitor of the city of Belém and for the local population, the field research also gauged the enterprises of food and drinks of the city. Based on these procedures, it is contextualized on culture, tourism, gastronomy and beer in the world, national, regional, which were fundamental for a more comprehensive analysis of the problem of research. The results indicate that the craft beers of Amazonian flavors have an attractive potential, however, there is no specific tourism planning for this product. This research aims to contribute to the studies about the relation between tourism and gastronomy in the city of Belém. At the end of this work it was suggested expanding the dissemination of this product for the local population, creating a Beer route. In order to put Belém in the global route of microbrews.

KEYWORDS: Tourism; Gastronomy; Belém; Beer And Flavors Amazon.

\section{Introdução}

O valor cultural do ato e do modo alimentar é cada vez mais entendido enquanto patrimônio imaterial, pois o alimento é identidade dos povos. Para o Ministério do Turismo - Mtur "a identidade gastronômica, enquanto elemento de identidade da cultura de um povo pode ser trabalhada como um atrativo turístico ao proporcionar para o turista o conhecimento da identidade cultural de determinada comunidade" (BRASIL, 2010, p.26).

Dias (2005) ressalta que a atividade turística impacta diretamente na cultura, de modo preservar as heranças culturais através da conservação de atrativos turísticos, a identidade cultural também pode ser fortalecida por meio das diferenças levantadas entre turista e comunidade, onde 0 sentimento de orgulho de sua identidade é exaltado, além da promoção e tolerância cultural, ou seja, os hábitos e costumes são respeitados de ambos os lados.

Gimenes (2005, p.192) "o indivíduo é capaz de relacionar determinado sabor a uma situação, a uma localidade, a uma fase de sua vida e até mesmo a um grupo social'. Logo a gastronomia está intimamente ligada às experiências vividas ao longo da vida, de forma que ao experimentar determinado prato você se torna suscetível a vincula-lo a algum acontecimento de sua trajetória. Da mesma forma que a gastronomia está conectada as práticas históricas e hospitalidade da comunidade receptora. 
A gastronomia é vista como uma forte aliada à atividade do turismo, em qualquer uma das regiões que compõe o território brasileiro, culinária local desenvolve-se no turismo através da curiosidade dos indivíduos por desbravar culturas e lugares diferentes do seu.

A gastronomia como patrimônio local está sendo incorporada aos novos produtos turísticos orientados a determinados nichos de mercado, permitindo incorporar aos agentes da própria comunidade na elaboração desses produtos, assistindo ao desenvolvimento sustentável da atividade (SCHLUTER, 2003, p. 70).

Pará, Belém, região de tantas manifestações culturais, cheiros, cores e sabores inigualáveis. Neste cenário dos frutos, raízes, madeiras, sementes e aromas de características únicas, exóticas e cheias de significados; a cerveja artesanal traz essa riqueza gastronômica da Amazônia paraense. Tendo a opção da descoberta dos cheiros e sabores de forma singular através da experiência da cerveja.

Neste contexto, a cerveja artesanal torna-se um atrativo para o turismo, pois carrega em sua produção, além da cerveja como um produto admirado pela população do Brasil e muitos países, os cheiros e sabores da gastronomia amazônica paraense. Diante disso, a problemática deste trabalho busca ter conhecimento se as cervejas artesanais dos sabores amazônicos são elementos atrativos para o turismo em Belém (PA).

Com base nessas problemáticas vigentes, 0 presente estudo objetivou promover as cervejas dos sabores amazônicos como elemento da valorização da cultura gastronômica paraense, e em consequência a atividade do turismo na cidade de Belém. E assim, expor a singularidade da gastronomia paraense, destacando a cultura das cervejas artesanais da região, retratando a gastronomia como meio cultural, e analisar as cervejas dos sabores como potencial indutor para o turismo em Belém.

Para a realização desse estudo, foram utilizadas algumas técnicas de pesquisa para a apropriação do(s) fenômeno(s) que se pretendiam analisar empiricamente. Para tanto, foi imprescindível a chamada pesquisa bibliográfica: a partir do registro disponível, pesquisas anteriores, documentos, livros, artigos, teses e outros (SEVERINO, 2007). Através, da visitação do estabelecimento observar e aplicar questionários para os clientes, com o objetivo de conhecer a opinião do turista em relação às cervejas como um atrativo da cidade de Belém. Por fim, realizou-se a pesquisa de campo com a população local, turistas, órgãos públicos além dos proprietários e gestores de bares e restaurantes de Belém.

De modo que a análise desta pesquisa se deu a partir da aplicação de questionários, que ocorreu no período de março a maio de 2016. As abordagens foram feitas nos principais pontos turísticos da cidade de Belém, como: Complexo Feliz Luzitânia, Mangal das Garças e Estação das Docas. Além da utilização das redes sociais e emails. Sendo que a partir das abordagens prospectou-se tanger a conclusão deste, tendo como finalidade superar as expectativas, de modo a afirmar que as cervejas artesanais dos sabores amazônicos possuem um amplo potencial econômico e turístico. De forma a somente agregar a região. 


\section{Turismo Cultural}

O próprio termo cultura vem do latim colere, que significa cultivar, criar, tomar conta e cuidar. Cultura significa o cuidado com a natureza (agricultura), o cuidado com os deuses (culto), e ainda o cuidado e a educação das crianças (puericultura: puer significa menino, puella, menina) (CHAUI, 2008).

A partir do século $X X$, cultura passa a ser compreendida em um campo no qual os agentes históricos ordenam símbolos e signos, as práticas e os valores, definem para si próprios o certo ou errado, bom e o ruim, o sentido da linha do tempo, o justo e o injusto, o que se pode ou não pode, na tentativa de ordenar a ideia de lei, "e, portanto, do permitido e do proibido, determinam o sentido da vida e da morte e das relações entre o sagrado e o profano" (CHUAl, 2008, p. 56).

Santos (2006. p.22) define que cultura pode ser associada às diversas manifestações artísticas; e também, associada aos veículos de comunicação de massa, ou seja, "ao se falar na cultura da nossa época ela é quase identificada com os meios de comunicação de massa, tais como o rádio, o cinema e a televisão".

Dentro desse novo turismo o aspecto de valorização da cultura está intimamente ligada à autenticidade, a identidade, ao patrimônio e as peculiaridade encontradas naquele local que logo o turista vai se identificando e buscando cada vez mais.

O patrimônio cultural pode ser entendido como um conjunto dos principais fatos de um grupo social, inerentes a memória e a identidade do mesmo, portanto, não é apenas o patrimônio, mas também os hábitos, costumes, as manifestações artísticas, os usos, a forma de vida diária, e a memória da sociedade, englobando por isso a cultura erudita e popular, envolvendo a dinâmica da cultura do ontem e do hoje.

Partindo da discursão sobre turismo versus cultura, turismo cultural surge dessas vertentes. Segundo Pérez (2009, p. 109-110; apud STEBBIS, 1996), "turismo cultural é uma vivência de participação em novas e profundas experiências culturais estéticas, intelectuais, emocionais e psicológicas". O turista cultural tem como objetivo a experiência e a valorização que está relacionada com a identidade do local visitado.

Nessa perspectiva de acordo com Schluter (2003), a gastronomia está tomando cada dia mais como mais um fruto para o turismo cultural, a busca pelas raízes da cozinha e também a forma de entender a cultura de um lugar por meio da gastronomia, ou seja, a cozinha tradicional está sendo vista como um elemento efetivo do patrimônio intangível das comunidades. 


\section{Gastronomia}

"A gastronomia é a história cultural da alimentação. Sua essência é a mudança, a temporalidade, a visão de passado como processo contínuo de perspectiva sobre tendências, sobre o constante e o eventual" (ARAÚJO et al., 2005, p.15), pois foi fundamental na vida e na evolução humana.

Segundo o autor Jean-Anthelme Brillat-Savarin, que era advogado, filósofo e gastrônomo, em sua obra de grande importância para o meio gastronômico, A Filosofia do Gosto, define a gastronomia como "o conhecimento fundamentado em tudo o que se refere ao homem, na medida em que ele se alimenta. Seu objetivo é zelar pela conservação dos homens por meio da melhor alimentação possível' (PANOSSO NETTO; GAETA, 2010; apud BRILLAT-SAVARIN, 2009, p.58).

A palavra gastronomia vem do idioma grego, o termo gaster (ventre ou estomago) e nomo (lei), literalmente traduzido "as leis do estômago". Tal termo foi criado pelo poeta, pensador, viajante e apreciador da boa mesa Asquestratus, viveu no século IV a.C. Como bom amante da cozinha que era gastou boa parte de suas posses viajando e buscando novos sabores. $O$ resultado de suas buscas foi a reunião em um acervo chamado de Hedypatheia, que nada mais é que a primeira definição da gastronomia, os prazeres que a comida oferece e as formas de se comer bem (FREIXA; CHAVES, 2012).

As cruzadas deslocaram os europeus em busca de especiarias e destruiu a agricultura local para condicionar as colônias as demandas e costumes mundiais. Houve um marco na humanidade o intercâmbio de culturas, alimentos, plantas e animais.

Na compreensão de Espirito Santo e Martins (2014) a gastronomia vem se tornando um potencializador do turismo, ou seja, vem se caracterizando como um atrativo turístico, partindo do entendimento que os hábitos alimentares e as formas de preparo de uma população a identificam e a torna única no universo gastronômico. Considerando que as rotas gastronômicas estabelecem a interligação dos homens e propagação da cultura local.

A concepção da culinária brasileira veio da mistura de três culturas, a indígena que já se encontrava alocada na região e cultivava para sua subsistência, a portuguesa que a partir das grandes navegações e pela necessidade de especiarias para cozinha europeia acabou influenciando o Brasil e a africana que chegou ao novo mundo como escravo, mas teve grande participação na história.

$\mathrm{Na}$ historicidade da culinária do povo africano dentro do Brasil herdaram-se alguns pratos, como: a moqueca baiana, a feijoada, a maniçoba e a utilização do azeite de dendê nos pratos, dando cor e sabor diferenciado. Dentro da Casa-Grande as senhoras portuguesas chamadas de sinhás e as negras escravas chamadas de mucamas, faziam adaptações dos doces feitos nos conventos e nas abadias do período da ldade Média e criações com as frutas que aqui encontravam. A exemplo das frutas cristalizadas e em calda, pão de ló, quindim, bolo de rolo, entre outros. 
Para os olhos do turismo as adaptações feitas dentro da culinária fizeram enriquecer a cultura das localidades, ou seja, o viajante além de buscar pelo prato nativo, o mesmo procura também a sua moldagem. Ferreira (2015) expõe que os sentidos e os significados culturais podem ser interpretados, para que assim possa ser desenhada a rotina da sociedade e seus hábitos alimentares.

\section{O cenário da gastronomia no Pará/Belém}

Finalmente se chega à soberana, sim, a culinária paraense! As cores, cheiros, sabores vindos dos rios e da floresta úmida; aliadas em sua essência as técnicas de cocção indígenas. E há de se desprender de todo o preconceito, para deleitar-se da mais autentica gastronomia do Brasil.

Moquear (assar ou pôr no moquém), sabrecar (queimar de leve ), tirar o pitiú (amaz odor forte, semelhante ao de peixe), tomar um caribé (mingau de farinha de mandioca), tomar o tacacá (uma espécie de sopa ou bebida composto de goma de tapioca, tucupi, camarões salgados e jambu, servido em cuias e extremamente quente) por volta das cinco da tarde, não esquecendo a murrinha (moleza no corpo) que bate depois de tomar aquele açaí papa e piora quando cai aquele toró (chuva forte). Pois então, a gastronomia paraense vai além de comida, ela se constituí em sensações e contextos, inexplicáveis quem vê de fora.

No livro Gastronomia do Pará: o sabor do Brasil (2014) relata a cronologia da gastronomia amazônica paraense. Há registros desde o século XIX de documentos da complexa culinária da posterior Província do Grão Pará:

[...] D’Abeville relaciona os peixes pirápen, parati, curemãaçu, e o peixe boi, como alimentos largamente utilizados pelos indígenas, que preferiam os produtos cozidos ou assados e tinham por hábito o uso de um tempero que, nas refeições, era adicionado gradativamente a boca, sendo constituído por sal e pimenta moída. A essa mistura denominavam jonquere (ESPIRITO SANTO, 2014, p.13; apud D'ABBEVILLE, 2008).

Já no século XVII o padre João Daniel relata nas prisões portuguesas suas análises sobre os hábitos amazônicos, dando origem à obra "Tesouro Descoberto no Máximo Rio Amazonas". Além de documentar alguns frutos como a manga, o tituribá (taperebá), o copuaçu (cupuaçu), açaí, ibacaba (bacaba), beribá (biribá), ginja, pitomba, ingá, castanha do Brasil (castanha do Pará) e muitos outros. (ESPIRITO SANTO; MARTINS, 2014).

Sem dúvidas os rios da Amazônia, em especial o paraense, impressionam com sua quantidade e diversidade de espécies da fauna ictiológica, de peixes. Segundo Rodrigues (SD) os seres aquáticos de pele (couro) e com escama superam 1200 espécies de peixes consumidos por humanos existentes na extensão hidrofluvial do Pará. 
Grande parte do colorido do Mercado do Ver-o-Peso, vem das frutas. A variedade é grande, doces ou cítricas, grandes ou pequenas, de diversas formas geométricas, bonitas ou outros que a aparência deixa a desejar. Que inspiram suas formas de consumos seja 'in natura' e/ou com farinha de mandioca, como sucos ou cremes e sorvetes.

E como não dar destaque ao domingo de Círio, como todos sabem o Círio de Nazaré é uma importante festa religiosa para o povo paraense. E no domingo logo após a principal romaria, se tem o tão famoso "almoço do Círio" onde as famílias se confraternizam acompanhadas de uma farta mesa com diversos quitutes paraense: pato no tucupi, maniçoba, creme de cupuaçu, são exemplos.

A cervejaria e restaurante paraenses "Amazon Beer", outro importantíssimo local para o trade turístico-gastronômico, utiliza os ingredientes amazônicos na fabricação de cervejas artesanais, como cerveja de açaí, bacuri, chocolate da semente do cupuaçu, entre outras. A cervejaria tem várias cervejas premiadas que dá visibilidade a cidade. A cachaça de Jambu, também é conhecida, encontrada no bar "Meu Garoto", famosa pela particularidade da folha de jambu e sua sensação que faz a boca tremer.

Outros bares e restaurantes são relevantes que fazem parte do trade gastronômico do Belém: Manjar das Garças, além de servi comidas regionais, o restaurante se encontra em um belíssimo equipamento turístico, - Mangal das Garças; Point do Açaí; restaurante Saudosa Maloca localizado na Ilha do Combú; os restaurantes da orla de Icoaraci, famosos pelas fartas chapas de peixe, camarões e carne; entre outros.

Espirito Santo e Martins (2014) cita como marco para a gastronomia e o turismo paraense os eventos de gastronomia. E em 2000, acontece em Belém a primeira versão do "Ver-O-Peso da Cozinha Paraense", outro evento que já faz parte do calendário turístico do Pará e da Amazônia é o "Comidinha de Praia", que ocorre no município de Salinas. Importante citar que em 2015, a tendência da gastronomia mundial, os foodtrucks, invadiram a cidade de Belém, o "Circuito Papa Xibé de FoodTrucks". No ano de 2016, - Mercado do Ver-O-Peso recebeu o projeto piloto para valorizar a gastronomia paraense, "Ver-a-Boia".

O "I Festival Amazônico de Cerveja" vem para corroborar com a pratica de produção de cervejas artesanais. Assim desejando entrar para o calendário nacional, sendo considerado o $1^{\circ}$ festival de cervejas artesanais do Norte e Nordeste, esse mercado de cervejas artesanais está em franca expansão no Brasil.

Em 2015, Belém recebeu o título Internacional de Cidade Criativa da Gastronomia, concedido pela Unesco. Hoje, a rede de cidades criativas é composta por 116 cidades, em todo o mundo, e em sete segmentos da indústria criativa e no Brasil apenas Belém (Gastronomia), Santos (Filmes) e Salvador (Música), possuem este título. A capital paraense torna-se referência mundial em gastronomia.

Por fim, diante deste cenário singular da gastronomia paraense esta pesquisa pretende promover as cervejas artesanais dos sabores 
amazônicos como elemento da valorização da cultura gastronômica paraense e, em consequência, a atividade do turismo na cidade de Belém.

\section{Turismo gastronômico}

Para Schluter (2003. p.70) "A gastronomia faz parte de uma nova demanda por parte dos turistas de atrativos culturais. O desenvolvimento do turismo cultural é estimulado em razão de sua capacidade de gerar receita [...]". Logo o turismo gastronômico é uma segmentação nova no mercado, mas antiga na geração de receita, pois consegue agregar valor em determinados costumes das localidades que produzem culinária peculiar ao paladar dos apreciadores.

Schluter (2003) destaca que a gastronomia é ocasionalmente um motivo para deslocar-se a um destino especifico, porém, para diminuir essa esporadicidade, recorre-se a criação de rotas turísticas, permitindo a integralização de elementos ermos da cultura com o produto de interesse do visitante. Isto posto, logo reforça a importância do turismo gastronômico para cultura da região. A consolidação das rotas gastronômicas favorece a simbologia e o patrimônio cultural e culinário. Assim as rotas voltadas as cervejas artesanais podem ser inseridas na comunidade, estas irão reforçar a cultura, os ingredientes e os produtos que ela complementa.

Para o turismo, a culinária local é uma forte estratégia de divulgação e promoção da localidade no âmbito cultural. E cada vez mais a gastronomia é motivo determinante para escolha do lugar que o turista irá viajar. " $A$ materialidade da gastronomia na estrutura do produto turístico contemporâneo tem sido impulsionada pela necessidade de revalorização de identidade local' (ESPÍRITO SANTO, 2014, p.26).

E no Pará não é diferente, a rica culinária regional é utilizada como estratégia para o fomento da atividade do turismo local. O mesmo autor fala que houve uma propagação pelos meios de comunicação brasileiros da gastronomia paraense das suas peculiaridades e herança indígena. " $A$ sustentabilidade do turismo gastronômico está relacionada com a manutenção de padrões de qualidade dos produtos e da composição dos pratos" (ESPÍRITO SANTO, 2014, p.35). O turismo gastronômico paraense está ligado à preservação do patrimônio tradicional e da qualidade da culinária em sua conjuntura do passado, do presente e do amanhã.

O turismo gastronômico no Pará pode ser trabalhado através da relação da comida enquanto ator social. Segundo Ferreira (2015, p.29-30) destaca que este fato "pode ser observado nas feiras livres e outros espaços públicos de Belém, em que exerce papel marcante na identidade local". "Uma satisfação não somente biológica, mas também social, econômica, cultural e identitária".

E é nesse contexto que o presente trabalho vem apresentar a singularidade da gastronomia paraense por meio das cervejas artesanais produzidas na região a partir de insumos silvestres e típicos. Analisando a variedade de sabores e assim ratificando o potencial indutor do turismo em Belém. 


\section{Cerveja: uma perspectiva do tradicional ao exótico}

A paixão pela cerveja não é tão recente. Aliás, a palavra cerveja é originada do latim cerevisia, derivada de Ceres, a deusa da colheita, da fertilidade e da força. O cereal, um dos principais ingredientes da cerveja, surgiu por volta de 9000 a.C na Ásia Ocidental, esses povos colhiam os cereais e transformavam em farinhas. Surge então a relação do pão e da cerveja ("o pão líquido"), embasando a lenda que diz "o que fixou o homem foi a necessidade de produzir pão e cerveja" (MORADO, 2009, p.22).

Morado (2009) no livro "Larousse da Cerveja" aponta registros sobre o aparecimento da cerveja antes de Cristo, como em pinturas rupestres que indicam a fabricação de uma bebida parecida à cerveja; antes do surgimento da escrita há registros em linguagem cuneiforme e hieróglifos; por volta de 6000 a.C estudos apontam a cerveja como moeda de troca; a peça suméria, Nonumento Blau, mostra a cerveja como oferenda à deusa Nin-Harra; a cerca de 2000 a.C os chineses produziam a cerveja de painço (Tsiou) também como oferenda aos seus ancestrais.

A cerca do ano de 1730 a.C o Império Mesopotâmico escreveu Código de Hamurábi nele consta registros relevantes sobre a papel da cerveja nesta sociedade, por exemplo: o cervejeiro se afogava em sua cerveja caso o sabor não o agrade; e também o pagamento da cerveja poderia ser feito apenas em cereais, não por dinheiro.

$\mathrm{Na}$ Babilônia, os exércitos dispensavam o cervejeiro das atividades militares em troca de suprir o exército com a cerveja; e as prostitutas fabricavam sua própria bebida para oferecer aos clientes. Já os egípcios produziam sua cerveja, conhecido porzythum, era uma bebida usada como tratamento de pele e também não podia faltar em cerimonias fúnebres (MORADO, 2009).

O autor ressalta que os germânicos e celtas podem ter sido influenciados pelos Trácios que dominavam um enorme território e graças aos movimentos migratórios levaram a cerveja que era considerada sagrada. Os celtas destacam-se na história da cerveja por suas receitas e técnicas de fabricação, o autor Plínio (23-79), em sua obra Naturalis Historia, os celtas produzindo cerveja na Gália e na Galícia. "O primeiro milênio da era cristã, celtas e germânicos eram os povos que mais produziam e consumiam a cerveja" (MORADO, 2009, p. 28).

Durante o início da era medieval, a cerveja se estabelecia como uma atividade caseira, produzida principalmente pelas mulheres, e consumida bastante por ser mais barato em comparação com o vinho; utilizada para tratamento de saúde, mas também em festas como inebriante e uma alternativa para substituir a agua que era de baixa qualidade.

Os mosteiros e abadias, devido suas instalações e organização, eram únicos em produzir cerveja em grande escala e de boa qualidade, direcionada aos monges e pobre, e vendida aos camponeses e peregrinos. Além destes, as casas episcopais e catedrais fazem parte da história da cerveja, tendo registros de produção e consumo da mesma. 
Foi também uma monja, beneditina alemã Hildegard Von Bingen, que escreveu o primeiro registro que se conhece, sobre a introdução lúpulo (Humuluslupulus L.) no processo de fabricação da bebida. No início apesar do amargor, o lúpulo foi utilizado para a conservação da cerveja, pois como antes não havia controle sobre o processo de fermentação. E depois da resistência inicial do gosto, por volta de 1400, o uso do lúpulo já havia conquistado a Europa, principalmente na Alemanha e nos países baixos. (MORADO, 2009).

Para Morado (2009) a evolução cervejeira sofreu cinco etapas entre o período medieval até a Renascença: primeira etapa foi à especialização da mão de obra, porém uma atividade casual e/ou um complemento de renda; na segunda etapa a produção da cerveja começa a se estabelecer em épocas do ano fora do plantio e colheita; a próxima diz a respeito da união espontânea dos produtores, e com o crescimento urbano os grupos cervejeiros locais tinham a capacidade de produzir durante o ano a bebida; na quarta etapa o início da industrialização, os cervejeiros aprimoram técnicas e melhorias no processo de fabricação da cerveja; na última etapa está descrita onde os estados e burgos assumem e regulam a produção local, transformando em negócio.

O descobrimento da América e a Reforma Protestante marcaram a Idade Moderna, as estruturas dos mosteiros quase foram destruídas pelas mudanças que a Reforma trouxe, a atividade cervejeira foi regulamentada e também houve desenvolvimento tecnológico. O primeiro registro sobre regulamentação da cerveja foi em 1487 decretada pelo Duque Albrecht IV, da Baviera.

Morado (2009) discorre que os séculos XV e XVI foram séculos importantes para a história da cerveja. A indústria cervejeira se desenvolveu, parte disso pelo alto preço do vinho, aumentando o mercado consumidor da cerveja nos países principalmente da Europa, na época um cervejeiro tinha status tanto social como político.

Também no século XVI, surge a cerveja Lager, o Duque Albrecht V proibiu certas cervejarias alemãs produzir cervejas no verão, então os cervejeiros tinham que guardá-las para se consumir no verão. A bebida era guardada em adegas frias e úmidas nos Alpes, essa forma de armazenamento acentuou o sabor e deixou a bebida mais leve e clara. Sabe-se que hoje, essa característica é dada pelas leveduras tem a tendência a não se flocular a baixas temperaturas.

Ainda no século XVII, surgiu a cerveja "pale ale", um procedimento importante para a história da cerveja, a secagem do malte através do coque (tipo de combustível derivado da hulha), isso deu a cerveja a característica da aparência mais clara, devido os grãos de cevada não serem torrados.

O século XIX houve uma melhoria no desenvolvimento da produção e do mercado da cerveja e graças a esse desenvolvimento cientifico e industrial que a cerveja é conhecida atualmente, como na cidade Pilsen na Boemia (Atual República Checa):

Outro avanço aconteceu no início do século XIX, quando Gabriel Sedlmayr II, de tradicional família cervejeira, desenvolveu um método de 
secagem via aquecimento indireto dos grãos, tornando o processo de produção do malte passível de total controle (MORADO, 2009, p.45).

A bebida passou a ser produzida em escala industrial, graças ao desenvolvimento e invenções como a máquina a vapor, sistema de refrigeração, os meios de transportes, a utilização do microscópio e termômetro na produção, a descoberta da formula da fermentação e pasteurização (na época as pesquisas sobre pasteurização foram direcionadas a produção da cerveja).

Nos Estados Unidos, no pós-guerra surgiu várias micro cervejarias nesse período, acompanhando o ritmo acelerado de desenvolvimento que o país se encontrava. Em 1972, os cervejeiros e cervejólogos da Inglaterra promoveram um movimento chamado CAMBRA (Campaign for Real Ale), visando incentivar os produtores à valorização e produção da autêntica cerveja Ale, essa campanha surge com a preocupação da produção em massa da cerveja. Outros movimentos, como o homebrewing ganharam destaque nesta década. (MORADO, 2009).

Com a globalização, final do século $X X$ e início do século $X X I$, a cerveja torna-se um produto comercial direcionada pelo marketing, há diversas fusões de cervejarias e assim o mercado se concentra em poucas empresas, o surgimento das muitas micro cervejarias levou a diversificação de cervejas. O consumidor torna-se exigente, indo atrás de produtos sustentáveis e de qualidade, e é importante ressaltar que as mulheres passaram a fazer parte do mercado consumidor.

A história da cerveja no Brasil é bem recente, Morado (2009) aponta que a Companhia das Índias Orientais trouxe a bebida no século XVI. No século XVII, o frade da Ordem dos Capuchinhos de Paris documentou sua experiência na Amazônia e ressalta o consumo de cerveja: a "cerveja do lugar que é muito boa por ser feita de milho, não é muito cara por haver abundancia deste gênero na terra e serem as águas boas e puras" (ESPIRITO SANTO, 2014, p.14; apud D’ÉVEREUX, 2007, p. 209).

Como os ingleses detinham de poder comercial sobre Portugal, até 0 final do século XIX as cervejas inglesas dominavam o mercado da bebida no Brasil. Além de umas poucas produções artesanais para consumo familiar, a fabricação era muito precária e repleta de dificuldade, como a refrigeração, já que as máquinas da época eram muito caras. Algumas cervejarias surgiram no sul e sudeste, por exemplo, a Imperial Fabrica de Cerveja Nacional (Cervejaria Bohemia), Cia. Cervejaria Brahma e Cia. Antarctica Paulista. (MORADO, 2009)

O século XX no Brasil foi marcado pela modernização do mercado cervejeiro, as mulheres passaram a fazer parte do mercado consumidor, os ambientes dos bares e botecos se reinventaram. Neste século surgiu a Cervejaria Paraense (Cerpa), em 1966, Skol (1967), Kaiser (1989), Primo Schincariol (1989). Em 1999, houve a fusão das cervejarias Cia. Antarctica Paulista e Cia. Cervejaria Brahma e assim nasceu a Companhia de Bebidas das Américas (Ambev) e posteriormente a InBev concentrando a maioria do mercado (MORADO, 2009). 
Para Morado (2009), a cerveja é a bebida alcoólica mais bebida no mundo e a cervejaria como mercado está consolidada no mercado. A tecnologia avançada trouxe aos produtores controle sobre a produção. $\mathrm{E}$ cada vez mais, o grupo de apreciadores e cervejeiros cresce dando destaque a movimentos intensos no mundo, como homebrewing, brewpubs (bares-cervejarias), microcervejarias e/ou cervejarias artesanais.

Na compreensão de Fagliari (2005, p. 54) "pratos e produtos típicos são elementos que podem ser facilmente trabalhados de forma a se tornarem atrativos turísticos". A partir desta analise as cervejas artesanais dos sabores amazônicos podem ser desenvolvidas como rotas gastronômicas, partindo da premissa que o mercado está favorável para este tipo de investimento.

Por mais que a região amazônica possua uma gama de insumos, para que haja o desenvolvimento das cervejas com sabores típicos, se faz necessária sensibilização dos órgãos responsáveis do turismo, pesquisa sobre o mercado através de profissionais capacitados e que compreendam a demanda e a oferta turística, o planejamento da iniciativa privada e governamental, a fim de buscar soluções e incrementos para o turismo cervejeiro e inserção da população local na elaboração organizacional do turismo gastronômico.

\section{Os sabores amazônicos da cerveja}

A heterogeneidade biológica amazônica favorece a fomentação da produção de cervejas artesanais com sabores regionais e assim impulsionando um mercado novo no estado. A produção dessas cervejas deixou de ser de pequena escala e passou a conquistar o mundo. $O$ que vem encantando os apreciadores não somente a produção, mas também a diversidade de ingredientes, sabores e aromas que podem ser agregados às cervejas.

Assim cultura cervejeira vem ultrapassando a forte tradição comercial no mercado belenense, pois a valorização desde produto aliado a singularidade dos sabores vem transformando o consumo das cervejas artesanais, ou seja, o apreciador não busca apenas a variedade, mas sim a sofisticação do sabor e a qualidade do produto.

A partir da análise dos tipos de cervejas comercializadas em Belém, encontra-se um dos principais sabores regionais e o mais presente nas refeições do dia a dia, este que foi aliado a um estilo tipicamente inglês: o stout é um gênero de cerveja mais encorpada e com o teor alcoólico bem altivo. A cerveja de açaí possui uma coloração escura e por ser uma stout, o seu sabor é mais apurado, o que a torna uma cerveja mais gastronômica.

Partindo da mesma concepção hoje se encontra no mercado outro insumo com sabor forte e característico da localidade e transpõe um sentimento regionalista. Produzida a partir do bacuri (Platoniainsignis), a cerveja de bacuri é uma das bebidas mais icônicas da região, pois retrata todo o paladar amazônida e sua característica mais forte é o aroma frutado. A aparência com um líquido dourado claro e límpido também se destaca, juntamente com a espuma consistente e branca. 
Para Morado (2009) as cervejas estilo Fruit Beer são uma boa harmonização de frutas com cervejas que vão muito além de sabores frutados. Conseguem se diferenciar pelo frescor, sabor e aroma, podendo torna-las uma bebida superior e diferenciada. Além de poderem ser harmonizadas com frutos do mar, carnes brancas, queijo brie e complementam a finalização das refeições.

Antes de fazer sucesso no Brasil a fora a priprioca (Cyperusarticulatus), já era muito utilizada em banhos aromáticos preparados pela erveiras da região, que atribuem à capacidade de trazer bons fluidos e energias.

De modo geral, as cervejas no estilo Red Ale que é um estilo inglês, é uma bebida com coloração âmbar a cobre avermelhado, porém são límpidas e a espuma que se forma na boca do copo tem uma tonalidade branca. Seu aroma é geralmente marcado pelo caramelo e seu sabor é adocicado, mas no final deixa um leve amargor (MORADO, 2009).

O estilo inglês, com a maturação da raiz da priprioca rendeu uma cerveja com aroma frutado diferenciado e encorpado, com o teor alcoólico de $6,0 \%$, consegue transmitir 0 equilíbrio da bebida com suas harmonizações.

O estilo belga associado o tapereba (Spondiasmombin) resultou em uma bebida singular ao paladar. Este fruto é típico americano, porém muito encontrado e cultivado na região amazônica, em áreas de terra firme ou de várzea. O fruto é muito apreciado na forma de sorvetes, sobremesas, sucos, em pratos sofisticados e também incorporados em bebidas alcóolicas. Em outras regiões é conhecido como cajá (Spondiasmombin) seu sabor é azedo e sua casca fina e amarelada a destaca na região.

Nativa da Amazônia brasileira, o cumaru (Dipteryxodorata), emana um eflúvio muito agradável, desde as sementes até a sua casca.

O cumaru é uma espécie nativa de múltiplas utilidades; sua madeira de boa qualidade, fácil de trabalhar e com aroma agradável, é vendida no comércio com o nome de cerejeira. Suas raízes, entrecasca e sementes, produzem a cumarina, princípio ativo que, além de ser utilizado nas indústrias alimentícias (doces e biscoitos), de cigarros e tabaco, indústrias de perfume como fixador é utilizado na produção de medicamentos como o xarope de cumaru ou lambedores caseiros, de largo uso popular e de eficácia comprovada cientificamente como antinflamatório e broncodilatador (PIMENTEL et al., 2012; apud CANUTO. 2008, p.2).

Conhecida também como fava-tonka ou baunilha brasileira, é um insumo bastante utilizado na indústria farmacêutica e também nas cozinhas dos grandes restaurantes espalhados pelo mundo.

O amalgama do cumaru com a IPA resultou em uma cerveja com espuma firme, com coloração âmbar, com um amargor elevado e aroma cítrico e fortemente frutado que remeter-se à própolis e a canela. Theobroma Grandiflirum, conhecida popularmente cupuaçuzeiro, essa espécie é nativa das floretas tropicais e é encontrado em larga escala nos estados do Pará, Maranhão, Rondônia. A cerveja de cupulate é bem distinta, pois traz consigo 
o estilo inglês que foi criado a partir das misturas de outras cervejas e o insumo extraído da floresta e que começou a ter uma nova utilidade.

O cacau é conhecido pelos pesquisadores como Theobroma Cacao, chamando também de cacaueiro. Começou a ser utilizado na produção desta cerveja de chocolate é o stout. Conhecida vulgarmente como erva chama, a Menthaarvensis $L$, foi combinada Imperial IPA com a erva chama resultou em uma cerveja de coloração âmbar, com boa formação e persistência de espuma, seu aroma é único que lembra eucalipto, porém remete a frutas cítricas, já o sabor lembra a tangeria e maracujá.

Também podendo ser considerada como witirain, por utilizar a agua da chuva, ela remete ao sabor característico da manga, por mais que utilize somente sua casca. Existem as de estilo Saison, que são cervejas que possuem uma produção de pequena escala, pois dependem da sazonalidade do insumo que será adicionado a ela. Pelo fato da produção ser feita em pequena quantidade, encontraram-se cervejas de pimenta de cheiro (Capsicumchinense 'Adjuma) e jambu (Acmellaoleracea). Ao incorporar a pimenta percebeu-se que a cerveja ganhou um frescor bem suave, porém uma picancia eminente. A cerveja de jambu notou-se a sua principal característica de amortecimento.

Diferente da produção comum, a cerveja de andiroba (Carapaguianensis) não foi utilizada o lúpulo, este que fornece o amargor a cerveja. Para consagrar-se como uma Imperial IPA, foi adicionada andiroba a bebida, assim perdendo o amargor forte que lhe é conferido pelo lúpulo. Assim tornando uma cerveja suave, com tonalidade escura e com sabor que não remetia a andiroba. Esta cerveja pode ser considerada uma Sainso, por ser produzida em pequena escala.

Em entrevista com Juarez Junior, o mesmo discorreu sobre a importância e a valorização da cultura cervejeira. O mesmo transpôs que a produção artesanal vem ganhando mercado nos últimos anos e que a cidade de Belém possui estrutura e produtos que possam suprir festivais e rotas gastronômicas, que hoje já são desenvolvidos em Blumenau. A partir desse entendimento pode-se considerar que o fator determinante para movimentar o mercado de cervejas artesanais com sabores amazônicos é o de transforma-las em produto principal das visitas, ou seja, tira-las da complementação e sim coloca-las em evidencia em um cenário favorável que a gastronomia paraense se encontra.

Em vista disso, o objetivo deste trabalho vem divulgar a singularidade da gastronomia paraense, a fim de destacar a cultura, os cheiros e sabores regionais a partir das cervejas artesanais, propondo-se a analisar o potencial indutor para o turismo em Belém. De forma a promover as cervejas dos sabores amazônicos como elemento da valorização da cultura gastronômica e como um componente fomentador do turismo. 


\section{Pesquisa de campo}

A identidade cultural paraense/belenense vem se tornando cada dia mais forte, pois o nascimento e a reconstrução dos novos sabores vêm agradando o paladar da comunidade, do visitante e consegue prospectar futuros viajantes. Essa nova percepção de gastronomia engloba também as bebidas e as frutas amazônicas que podem ser encontradas em cervejas, bebidas alcoólicas apreciadas no mundo todo, sendo que no Estado do Pará esta peculiaridade vem enriquecendo a cultura local.

O questionário da população local foi dividido em três partes. A primeira parte objetivava identificar o perfil socioeconômico dos respondentes, por meio das seguintes questões: faixa etária, gênero, estado civil, nível de escolaridade, faixa de renda; a segunda parte tinha por objetivo levantar dados sobre a gastronomia no âmbito do turismo da cidade de Belém, e por fim, a terceira parte, visava levantar dados sobre o potencial das cervejas dos sabores amazônicos como elemento atrativo para o turismo da cidade de Belém.

Constata-se que $59 \%$ dos entrevistados são mulheres e $41 \%$ são homens. Verifica-se que $31 \%$ dos entrevistados correspondem à faixa etária de 25 a 34 anos, os $26 \%$ correspondem à faixa etária de 15 e 24 anos. Analisou-se o estado civil dos entrevistados, constatou-se que $71 \%$ eram solteiros, os $20 \%$ correspondem aos casados, estes que estavam acompanhados de suas esposas, família ou entre amigos. Dos entrevistados, $57 \%$ encontram-se formados em algum curso do nível superior ou em processo de formação. Os $27 \%$ correspondem às pessoas já pós-graduadas ou no andamento do curso. Entretanto, apesar de a maioria possuir alto grau de escolaridade a remuneração é baixa, pois $51 \%$ informaram que recebem até 3 salários mínimos e 30\% possuem renda entre 4 e 6 salários mínimos.

Quando se foi questionado sobre o potencial gastronômico no turismo em Belém a resposta foi unanime, os entrevistados acreditam neste potencial. Isto posto, percebe-se a compreensão da população local está certa do potencial turístico da gastronomia. Isso se deve pela peculiaridade da culinária paraense. Espirito Santo e Martins (2014) salienta que a globalização imprime no contexto atual o reconhecimento das diferenças. Consequentemente prospecta no fortalecimento do destino.

Aferiu-se que $94 \%$ dos entrevistados divulgam a gastronomia de Belém para atrair mais visitantes, o porquê desta pergunta apenas confirma a opinião da resposta anterior, os entrevistados divulgam, pois consideram como um dos principais elementos da cultura do paraense. Dessa forma, compreende-se que a população local possui entendimento acerca de sua identidade gastronômica. De modo, que $84 \%$ dos entrevistados entendem que a cidade tem estabelecimentos de comidas típicas. Entretanto, se ressalta que a maioria conhece poucos estabelecimentos e compreendem que há poucas opções, principalmente para o turista. A maioria dos exemplos citados pelos participantes foi, às barraquinhas de rua, o Ver-oPeso, e Estação das Docas. Isso só reforça que a comunidade local não 
possui o pleno conhecimento dos estabelecimentos que desenvolvem a gastronomia da região.

Dos entrevistados $71 \%$ são apreciadores de cerveja. Quando questionado sobre já terem experimentado cervejas de sabores amazônicos. $57 \%$ dos entrevistados já experimentaram as cervejas artesanais dos sabores amazônicos. Logo percebe-se que a população paraense aprecia estas bebidas, de forma a compreenderem seu potencial gastronômico e turístico. Os $43 \%$ dos abordados, reflete que ainda há pessoas dentro da cidade que não degustaram as cervejas de sabores regionais produzidas na região.

Durante a pesquisa de campo foram visitados estabelecimentos de alimentos e bebidas e pontos turísticos da cidade. Dessa forma, $53 \%$ dos entrevistados frequentam principalmente os estabelecimentos que produzem e comercializam as cervejas dos sabores amazônicos. Os $47 \%$ dos entrevistados afirmaram em não frequentar esses estabelecimentos, por motivos religiosos, preferencias musicais e por fidelização há outros locais.

$E$ quando perguntado aos moradores de Belém se indicariam as cervejas dos sabores amazônicos, a maioria, 89 \% dos abordados indicam e/ou indicariam este produto. Os dados apresentados apontam que a população local acredita neste produto como um diferencial para a cidade. Os $11 \%$ afirmam que ainda não tiveram a oportunidade de experimentar as cervejas artesanais dos sabores amazônicos e não frequentam estabelecimentos que a comercializam.

$91 \%$, dos abordados acreditam que as cervejas dos sabores amazônicos podem ser consideradas como um futuro produto turístico para cidade de Belém. Os entrevistados argumentam que a bebida apresenta em sua composição a identidade gastronômica da região, ou seja, uma cerveja que valoriza a identidade amazônica. Segundo Fagliari (2005, p.55) "as bebidas também podem tornar-se ícones de localidades e mesmo de países".

Abaixo estão expostos os resultados das análises dos dados alcançados da investigação desenvolvida com os turistas. Foram aplicados questionários direcionados aos turistas contendo 16 perguntas, tendo como objetivo investigar o perfil socioeconômico dos respondentes, conhecer a visão dos turistas sobre gastronomia e turismo, principalmente relacionado à cidade de Belém e ainda visava levantar dados sobre o potencial das cervejas artesanais dos sabores amazônicos como elemento atrativo para o turismo da cidade de Belém.

Dentre os entrevistados $67 \%$ eram homens e $33 \%$ de mulheres que responderam ao questionário se deve ao fato das mesmas se colocaram a frente, e também por algumas estarem viajando desacompanhadas ou entre mulheres.

A mostra de faixa etária dos turistas abordados durante a aplicação dos questionários. Sendo que 31\% correspondem aos que estão entre 25 a 34 anos, $20 \%$ corresponde a faixa etária de 15 a 24 anos, 20\% corresponde a faixa etária entre 45 e 54 estavam visitando a cidade com a família ou acompanhados de seus cônjuges. Do mesmo modo que os abordados da 
faixa etária de 55 a 64 anos, que condiz a $12 \%$ dos abordados vieram conhecer a cidade com seus consortes ou sozinhos. De forma atesta-se que esta situação esteja ligada diretamente as circunstancias de visita à cidade durante feriados ou férias trabalhistas.

Perceber que o estado civil dos entrevistados é um paralelo com suas faixas etárias. Assim os $41 \%$ dos entrevistados eram casados, isso demonstra que as viagens entre casais ainda continuam em alta. Os 33\% correspondente ao estado civil de solteiro, estavam de passagem pela cidade a estudo, trabalho ou até mesmo a lazer, porém percebeu-se que estes não estavam sozinhos, e sim acompanhados de amigos.

Dentre os visitantes abordados, grande parte dos $74 \%$ já concluiu o ensino superior, outra pequena parcela ainda está em fase de conclusão. Os $23 \%$ dos entrevistados estavam em fase de conclusão do ensino médio. Os $3 \%$ dos abordados já eram pós-graduados, dando a eles uma independência maior em relação a sua viagem, ou seja, o poder de escolha e a facilitação de locomoção na cidade.

À renda dos entrevistados, a pesquisa não entrou no mérito da ocupação de cada indivíduo. $34 \%$ dos entrevistados informaram que recebem de 4 a 6 salários mínimos. Sendo que nesta pesquisa, 58\% dos entrevistados são da cidade do Rio de Janeiro, $14 \%$ da cidade de São Paulo, também foram entrevistados visitantes que moram, por exemplo, em Belo Horizonte, Fortaleza e São Luís.

Dentre os entrevistados $93 \%$ tem interesse de experimentar os pratos típicos da localidade, os turistas abordados nesta pesquisa argumentam que através da culinária local pode-se conhecer a cultura da região. Dessa forma, entende-se que a culinária local se destaca pela sua autenticidade, isso demonstra que o turista ao visitar a região procura conhece-la. E 7\% destes afirmaram não ter interesse em conhecer os pratos típicos dos locais visitados.

Quando questionado a respeito do conhecimento prévio dos visitantes em relação à culinária paraense, $91 \%$ dos entrevistados afirmaram que já tinham informação sobre a culinária local, sendo que uma pequena parcela dessa amostragem alegou que já havia provado os pratos típicos em visitas anteriores ou em outros estados que fazem a comercialização dos pratos locais; $9 \%$ dos abordados garantiram que ainda não haviam escutado sobre a gastronomia local.

Os meios e instrumentos de comunicação, como internet, televisão, eventos e boca a boca, podem ser utilizados para promoção da gastronomia paraense, uma vez que eles imprimem a sensação e emoção de quem a experimenta. A culinária paraense é vista pelo turista como aromas, cores e saberes diferentes, propriedade ainda não reconhecidas pelo paladar. Por isso pode-se afirmar que as cervejas artesanais dos sabores amazônicos levam o turista a compartilhar das mesmas emoções e sensações desfrutadas através da experiência gastronômica.

Constatou-se que $69 \%$ dos entrevistados tinham a curiosidade em conhecer a culinária paraense e esta era uma de suas principais motivações 
em conhecer a cidade. Na opinião da maioria dos turistas, a culinária paraense desperta curiosidades, pois é exótica e pela variação de cores e sabores que a permeiam. Logo nota-se que a gastronomia paraense vem se firmando no cenário nacional e mundial através dos meios de comunicação.

Assim sendo, a identidade gastronômica paraense é difundida em escala nacional e internacional, isso se deve ao advento da globalização. Entende-se que a valorização da culinária regional se estende ao visitante, logo o mesmo se sente atraído pela singularidade da culinária paraense. Da mesma forma que as cervejas artesanais vêm a motivar a viagem de turistas que tem por disposição apreciar estas bebidas.

Indagou-se sobre a ralação as frutas experimentadas pelos turistas. Logo $89 \%$ dos entrevistados garantiu que experimentou as frutas típicas da região, como: cupuaçu, bacuri, tapereba, açaí, manga, muruci, pupunha e outras. Isso demonstra a interação do visitante com a população local através da visitação as feiras e pontos turísticos da cidade. Analisou-se que os $11 \%$ que ainda não tinham tido a experiência de degustar as frutas típicas do estado, possuíam um largo interesse em provar, porém o seu tempo na cidade não lhe proporcionou tal experiência.

Apresentou-se o questionamento acerca da apreciação do visitante sobre cervejas. $69 \%$ dos entrevistados afirmou que apreciam cervejas, pois entendem que estas bebidas estão inseridas no cotidiano do brasileiro, de modo que os happy hour é um instrumento utilizado para interação social. Sendo que os $31 \%$ dos abordados atestam que sua não apreciação por cervejas está ligada a preferência por outra bebida, questões médicas, religiosas e por idade.

Quando questionado sobre já terem a experiência de experimentar as cervejas artesanais de sabores amazônicos $62 \%$ dos visitantes abordados afirmaram que já tinham experimentado algumas das cervejas artesanais dos sabores amazônicos. Por consequência 38\% dos entrevistados ainda não tinham experimentado as cervejas artesanais dos sabores amazônicos.

Perguntou-se sobre se os entrevistados indicariam cervejas artesanais de sabores amazônicos. $73 \%$ dos entrevistados indicariam as cervejas em questão. Essa porcentagem indica que os entrevistados podem difundir as cervejas a partir do "boca a boca". Segundo Leal e Almeida (2015) o turismo cervejeiro é uma tendência de mercado para o turismo gastronômico. Os autores apontam também que várias regiões do mundo já tem o turismo cervejeiro consolidado. Frisa-se que para consolidar este seguimento em Belém é necessário estruturar a receptividade do turista.

Percebeu-se que $83 \%$ dos turistas entrevistados acreditam nas cervejas dos sabores amazônicos como um futuro produto turístico. As argumentações dos turistas em relação ao produto foram bastante positivas, vendo a cerveja como um diferencial para a região, relacionando ao clima tropical como uma bebida refrescante, uma bebida que valoriza a identidade regional, e além de ser uma das bebidas mais consumidas e popularizadas no mundo.

Isto posto interpreta-se que as cervejas são bebidas extremamente versáteis e de fácil aceitação. Morado (2009) também destaca que existem 
incontáveis apreciadores de cervejas pelo mundo e que estes buscam por sabores novos. Assim as cervejas artesanais com sabores amazônicos tendem a atiçar a curiosidade destes apreciadores, de forma a aumentar 0 fluxo de turista na cidade a partir da fundamentação de um roteiro.

Consequentemente compreende-se que as cervejas artesanais dos sabores amazônicos despertam o interesse tanto nos apreciadores quanto nos que não consomem a bebida. Contudo os mesmos entendem que a bebida tem um forte potencial turístico, ou seja, elas se destacam no âmbito do turismo gastronômico. De forma que a biodiversidade amazônica favorece a inserção de sabores novos no mercado, e estes contribuem para $o$ incremento da economia.

A pesquisa também procurou abordar os gestores dos órgãos públicos, para que os mesmos pudessem discorrer sobre o tema do estudo. Buscou-se a colaboração através de ofícios com a Coordenadoria Municipal de Turismo (BELEMTUR).

Em entrevista concedida pela Srtä. Bianca Franco, Diretora da BELEMTUR, respondeu o questionário de pesquisa e comentou sobre as ações realizadas pela coordenadoria. A mesma acredita no potencial das cervejas dos sabores amazônicos e crê que a inserção deste produto nos eventos de promoção de Belém e do estado como um todo só vem a reafirmar acerca do potencial gastronômico paraense. De modo, que a partir dos incentivos dos eventos a inserção destes produtos em feiras e salões de exposições poderá colocar a cidade de Belém na rota turística mundial.

Partindo do entendimento do contexto, analisa-se que a população local já está absorvendo a cultura de consumo de cervejas artesanais, da mesma forma que o turista também. Logo a produção de cervejas artesanais com sabores amazônicos vem incrementando a economia local a partir da mudança de habito dos consumidores. Assim percebendo a necessidade de ampliar a valorização da gastronomia paraense onde as cervejas estão inseridas, de forma a prospectar um roteiro cervejeiro.

Conseguiu-se entrevistar ao todo 08 estabelecimentos, a aplicação dos questionários se dividiu em conhecer o estabelecimento, o nível de conhecimento do dono em relação à gastronomia local, no controle da receptividade e no consumo de turistas, no interesse de produzir e de revender cervejas artesanais dos sabores amazônicos e na percepção do empreendedor em relação da valorização das cervejas artesanais pelo turista, de forma a transforma-la em um atrativo turístico.

Dentre os proprietário e gestores de estabelecimentos, estes veem a gastronomia paraense altamente promissora, pois a riqueza de insumos só incrementa a peculiaridade. Consequentemente valorização tende a aumentar gradativamente com a globalização e difusão de informações. Schluter (2003) frisa que os elementos tradicionais gastronômicos vêm alcançando destaque e seu crescimento se deve a caracterização da valorização da culinária regional.

Atestou-se nas abordagens realizadas grande parte, quando perguntado sobre a atratividade gastronômica das cervejas artesanais para 
população local, se afirmou a importância de propagar essa cultura a partir do mercado interno, ou seja, popularizar as cervejas e fazer difundir esse segmento do mercado. A identidade gastronômica da região tem que ser planejada de forma inovadora, respeitando a tradição e seus atores, para assim possa valer do conceito de valorização de elementos regionais.

A pesquisa teve como principal relevância a promoção da gastronomia paraense através da produção das cervejas artesanais, de modo a prospecta-la como um atrativo turístico. Os diálogos tecidos com a população local, turistas, órgãos públicos e estabelecimento que produzem e comercializam essas bebidas, só confirmou as expectativas que cresciam ao longo da pesquisa.

\section{Conclusão}

Neste estudo, analisaram-se as possibilidades e desafios pertinentes as cervejas artesanais dos sabores amazônicos como elemento atrativo para o turismo de Belém do Pará. Antes da análise dos resultados de pesquisa, foi levantada a discussão critica acerca dos assuntos que abrangem o tema escolhido: cultura, turismo e gastronomia no âmbito mundial, nacional, regional.

Durante a investigação a respeito do tema, buscou-se evidenciar a gastronomia vista do valor cultural, que a identidade gastronômica faz parte da cultura de uma região, o visitante busca desvendar a cultura regional, e os produtos derivados a partir desse meio cultural. Frisando também os insumos utilizados na produção dessas bebidas, como: frutas, ervas, sementes e raízes, que são típicas da região amazônica.

Buscou-se apresentar a gastronomia paraense a partir do desenvolvimento deste trabalho, pois parte-se do entendimento que o leitor final tenha o entendimento mínimo da culinária local. A partir desta perspectiva, inserir as cervejas artesanais como um elemento cultural da gastronomia regional.

A partir desta pesquisa que as cervejas dos sabores amazônicos têm potencial para induzir o turismo na cidade, haja vista que sua inovação, relacionando uma cerveja que foge das convenções da indústria cervejeira com um valor cultural, os elementos da gastronomia regional. Ao longo da investigação se vê um grande potencial em Belém para o chamado turismo gastronômico, os visitantes têm acesso através das várias tecnologias sobre a peculiar culinária paraense.

Importante expor que o mercado das cervejas artesanais e/ou especiais está em crescente desenvolvimento, os amantes desta bebida buscam cada dia mais especializar-se sobre este universo. Em Belém, nos últimos anos surgiram clubes cervejeiros, lojas e bares que oferecem além de uma variedade de cervejas, mas também cursos, palestras e workshop sobre esta apreciada bebida.

E neste universo cervejeiro, acontecem vários eventos e concursos de cervejas em toda parte do mundo, fazendo com que este público desloquese às cidades dos eventos, mas também levar as cervejas para este lugar. 
Neste contexto, há cervejas dos sabores amazônicos que vêm se destacando nestes concursos, inclusive sendo premiadas, com isso essas cervejas carregam consigo uma proposta que utilizam insumos nativos, relacionando a cerveja com a cidade de Belém.

Percebe-se durante a pesquisa com os visitantes que as cervejas dos sabores amazônicos já são bastante conhecidas. A maioria vem à cidade, inclusive muitos buscam conhecer este produto e até levar como suvenires para seus amigos, parentes ou consumo próprio.

Os órgãos públicos de turismo, BELEMTUR e Secretaria de Turismo (SETUR) fazem um trabalho de divulgação da gastronomia, porém, a BELEMTUR não tem um projeto especifico sobre essas cervejas. Infelizmente investigou-se apenas o trabalho da SETUR divulgado pela mídia, pois não se obteve resposta do órgão para uma entrevista.

Então, fica visível que o potencial das cervejas como indutor para turismo de Belém existe e precisa ser aprimorado através da parceria dos órgãos públicos com os estabelecimentos que produzem e/ou comercializam esse produto para que eles possam criar estratégias para atrair mais turistas e colocar cada vez mais essas cervejas em festivais e eventos cervejeiros no âmbito regional, nacional e internacional.

É proposto então que os órgãos de turismo responsáveis incentivem e criem condições para cada vez mais os estabelecimentos produzirem suas próprias cervejas e de preferência com insumos amazônicos. E em parceria com os clubes de cerveja proporcionar um suporte para os empresários na área para que os estabelecimentos sejam referência em qualidade do produto e atendimento aos consumidores.

Outra proposta é a criação de um roteiro das cervejas amazônicas direcionado para o público amante da cerveja, moradores e turistas em geral para que Belém entre nas rotas da cultura cervejeira em nível regional, nacional e até internacional. Assim, o participante do futuro roteiro irá conhecer além do mundo das cervejas, mas também da gastronomia local e principalmente dos sabores amazônicos das cervejas.

E também, neste mundo tecnológico se pode pensar na criação de um aplicativo sobre a gastronomia, que mostre ao usuário as histórias e curiosidades sobre a culinária local, inserindo as cervejas como um produto desta gastronomia. E assim através de um banco de dados, o usuário possa achar onde comercializam os produtos, desde os pontos de açaí ou barriquinhas de comidas típicas, até restaurantes e cervejarias famosas localizados na cidade de Belém, onde os moradores e visitantes pudessem opinar e dar pontuações aos serviços, de acordo com cada realidade.

Com isso o presente que teve como objetivo promover as cervejas dos sabores amazônicos como elemento da valorização da cultura gastronômica paraense e em consequência a atividade do turismo na cidade de Belém, alcançou o esperado, pois a partir da análise da pesquisa de campo foi concluído que essas cervejas são indutores para o turismo, ressaltando que as mesmas podem ser desenvolvidas de forma que se aproveite todo o seu potencial. De forma a promover a localidade, os 
produtos utilizados para a produção das cervejas, e os estabelecimentos que as produzem/comercializam.

\section{Referências}

ARAÚJO, W.M.C. et al. Da alimentação a gastronomia. São Paulo: UNB, 2005.

BENI, M. Análise estrutural do turismo. São Paulo: SENAC, 2000.

BRASIL. Ministério do Turismo. Turismo Cultural: orientações básicas. 3 ed. Brasília: 2010. Disponível em: $<$ http://www.turismo.gov.br/sites/default/turismo/o ministerio/publicacoes/do wnloads publica coes/Turismo Cultural Versxo Final IMPRESSxO .pdf>. Acesso em: 03 abr. 2015.

CHAUI, M. Cultura e democracia: Revista latino americana de Ciencias.Sociales. Ano 1, $n^{\circ} .1$ (jun. 2008). Buenos Aires :CLACSO, 2008.

DIAS, R. Introdução ao turismo. São Paulo: Atlas, 2005.

ESPIRITO SANTO, Álvaro Negrão do. A construção do Pará: os três primeiros séculos (XVII a XIX). In: ESPIRITO SANTO, A.N.; MARTINS, F.J. Gastronomia do Pará: o sabor do Brasil. Belém: Abresi; A Senda - Artes, 2014.

ESPIRITO SANTO, A.N.. A gastronomia como expressão do patrimônio cultural imaterial luso-amazônica: das heranças históricas ao cenário pósmoderno. In: ESPIRITO SANTO, A.N.; MARTINS, F.J. Gastronomia do Pará: o sabor do Brasil. Belém: Abresi; A Senda - Artes, 2014.

ESPIRITO SANTO, A.N.; MARTINS, F.J. Gastronomia do Pará: o sabor do Brasil. Belém: Abresi; A Senda - Artes, 2014.

FAGLIARI, G.S. Turismo e Alimentação: Análises introdutórias. Ed. Roca, São Paulo, 2005.

FERREIRA, B.A.L., 2015. Comida de Esquina: comensalidade em torno do carros do cachorro quente em Belém-PA. Dissertação de Mestrado. Universidade Federal de Pará. Belém, Pará. Brasil.

FREIXA, D.; CHAVES, G. Gastronomia no Brasil e no mundo. 2 ed. 2. reimp. Rio de Janeiro: Senac Nacional, 2012.

GIMENES, M.H.S.G. Sentidos, sabores e cultura: a gastronomia como experiência sensorial e turística. In: PANOSSO NETTO, A.; GAETA, C. (Org.). Turismo de Experiência. 1ed.São Paulo: SENAC, 2010, v. 1, p. 187202.

MORADO, R. Larousse da Cerveja. Larousse do Brasil.1ed São Paulo, 2009.

PANOSSO NETTO, A.; GAETA, C. Turismo de experiência. São Paulo: Senac, 2010.

PÉREZ, X.P.Turismo Cultural. Uma visão antropológica- El Sauzal: ACA y PASOS, RTPC. 2009. 
PIMENTEL, J.V.F. Cultivo do cumaru (Amburana cearensis) em diversos sistemas de produção no semiárido. Campina Grande, 2012. Tese (Doutorado em Engenharia Agrícola). Universidade Federal de Campina Grande.

SANTOS, J.L. O que é cultura .São Paulo : Brasiliense, 2006.

SCHLÜTER, R.G. Gastronomia e Turismo. São Paulo: Aleph, 2003.

SEVERINO, A.J. Metodologia do trabalho científico - 23 ed. rev. e atualizada - São Paulo: Cortez, 2007.

Alessandra de Almeida Pereira: Universidade Federal do Pará, Belém, PA, Brasil.

E-mail: alessandraparnund@gmail.com

Link para o currículo Lattes: http://lattes.cnpq.br/6381641298264039

Brenda Cristina Moraes Lima: Universidade Federal do Pará, Belém, PA, Brasil.

E-mail: brenda.lima16@gmail.com

Link para o currículo Lattes: http://lattes.cnpq.br/7885759719422765

Diogo Domingos Barata dos Santos: Universidade Federal do Pará, Belém, PA, Brasil.

E-mail: diogo.barata@outlook.com

Data de submissão: 28 de outubro de 2016

Data de recebimento de correções: 17 de abril de 2017

Data do aceite: 17 de abril de 2017

Avaliado anonimamente 